\title{
A POLARIZAÇÃO POLÍTICA BRASILEIRA E OS EFEITOS (ANTI) DEMOCRÁTICOS DA DEMOCRACIA DELIBERATIVA
}

\author{
Maurício Martins Reis* \\ Catharine Black Lipp João ${ }^{1 *}$
}

Resumo: O presente artigo pretende analisar os efeitos da deliberação coletiva com polarização política sob os ideais moral e epistêmico da democracia deliberativa. Serão abordadas as teorias sobre o comportamento intergrupal e a influência da polarização sobre os indivíduos e os grupos, para então serem examinados os pressupostos da democracia deliberativa e a sua prática na dinâmica do Tribunal do Júri. O método científico envolve uma abordagem indutiva, com pesquisa explicativa e com procedimento bibliográfico.

Palavras-Chave: Conflito intergrupal. Deliberação coletiva. Democracia Deliberativa. Polarização de grupo. Tomada de decisão.

\section{BRAZILIAN POLITICAL POLARIZATION AND THE (ANTI) DEMOCRATIC EFFECTS OF DELIBERATIVE DEMOCRACY}

\begin{abstract}
This paper aims to analyze the effects of collective deliberation with political polarization under moral and epistemic ideals of deliberative democracy. It will be discussed the theories about intergroup behavior and the influence of polarization on individuals and groups, to then be examined the principles of deliberative democracy and its practice in the Jury's dynamics. The scientific method involves an inductive approach, with explanatory study and bibliographic procedure.
\end{abstract}

Keywords: Intergroup conflict. Collective deliberation. Deliberative democracy. Group polarization. Decision-making.

\footnotetext{
* Doutor em Direito Público pela Universidade do Vale do Rio dos Sinos (Unisinos). Doutor em Filosofia pela Pontifícia Universidade Católica do Rio Grande do Sul (PUCRS). Professor da Faculdade de Direito e do Programa de Mestrado da Fundação Escola Superior do Ministério Público (FMP) e do Instituto de Desenvolvimento Cultural (IDC). Endereço Eletrônico: mauriciomreis@terra.com.br.

* Mestranda em Direitos Indisponíveis, sob orientação do Prof. Dr. Anízio Pires Gavião Filho pela Fundação Escola Superior do Ministério Público (FMP). Especialista em Direito Público pela mesma instituição. Advogada. Endereço eletrônico: catharinejoao@gmail.com
} 


\title{
1. Introdução
}

\author{
"Busquei a imagem da própria democracia, com suas \\ inclinações, seu caráter, seus preconceitos e suas \\ paixões, para aprender o que temos a temer ou esperar \\ de seu progresso". \\ Alexis de Tocqueville. Democracy in America, 1904
}

“Coxinha", “ditador", "direita delirante", "fascista", "bolsominion", “olavete", "golpista", "machista", “entreguista", “racista", "homofóbico", .... "Mortadela”, “corrupto", "esquerda caviar", “cubano", "petista", "lulista", "bandido", "feminazi”, “comuna", "esquerdopata", "abortista", .... Esses são apenas alguns dos termos e expressões frequentemente usados com conotação ofensiva a quem se posiciona, respectivamente, como politicamente de "direita" ou antipetista e de "esquerda" ou petista, hoje em dia, no Brasil.

É de conhecimento comum a maneira de se descrever a afetada atuação do indivíduo sob a influência da sua aglomeração em maiores ou menores coletividades, "em particular o súbito desaparecimento, em estado de excitação, de restrições morais e modos civilizados de pensar e sentir, a súbita erupção de impulsos primitivos, infantilismos e propensões criminosas" (SCHUMPETER, 2003, p. 257), sendo que, segundo o contexto ora em análise pelo autor, todos os parlamentos, comissões, conselhos, etc. "exibem, embora atenuadas, algumas das características que se destacam tão gritantemente no caso da multidão, em particular um sentido reduzido de responsabilidade, um nível mais baixo de energia de pensamento e maior sensibilidade a influências não-lógicas” (SCHUMPETER, 2003, p. 257). Assim, a partir da identificação do indivíduo em um grupo, tende a se ausentar o elemento de racionalidade do cidadão comum, de modo que "a mera afirmação, muitas vezes repetida, conta mais do que um argumento racional, assim como o ataque direto ao subconsciente, que toma a forma de tentativas de evocar e cristalizar associações agradáveis de uma natureza inteiramente extraracional”. (SCHUMPETER, 2003, p. 257-258).

No Brasil, os “antipetistas" e os "petistas" são basicamente dois grupos em conflito constante que se manifestam não apenas nos representantes das instituições públicas, mas também por todos os representados nas redes sociais, nos seios familiares, nas escolas e universidades, nos locais de trabalho, nas confraternizações com os amigos, dentre outras situações características da reunião ou associação de um conjunto de pessoas. Não existem a 
rigor restrições com relação ao palco dessas animosidades. Nessas interações, não são raras as situações em que se percebe difusa a separação do ser diante de sua posição política, tanto em relação a si, quanto na sua consideração sobre o outro. Parece predominar a ideia de que aos indivíduos só cabe escolher um dos lados e defendê-lo ao máximo, ignorando quaisquer concepções opostas que, antes de sua escolha, até poderiam ter aquiescido. Para além de serem irrefletidas as "políticas" em si com as respectivas ideias e noções argumentadas ante a beligerância de uma ideologia cega que predomina, confia-se sobremaneira nas figuras carismáticas dos líderes dos grupos que as anunciam.

À semelhança da acirrada eleição norte-americana disputada entre Donald Trump e Hillary Clinton em 2016, no ano das eleições presidenciais brasileiras de 2018 sobressaíram-se dois grupos de aspectos políticos claramente opostos. Os "de direita" (ou melhor, os "antipetistas") em favor do presidente eleito Jair Bolsonaro e os "de esquerda" (ou melhor, os favoráveis ao PT e aqueles para quem “ele [Bolsonaro] não") em favor do candidato Fernando Haddad, misturado à figura do seu apoiador, o ex-presidente Lula, que pessoalmente estava impedido de representar o partido nestas eleições. Esses grupos opostos já tinham delimitado os seus contornos à época do impeachment da ex-presidente Dilma Rousseff em 2016, momento no qual a sua rivalidade fica clara pela votação da Câmara dos Deputados: o PT teve 60 votos contra e 0 votos a favor, e o PMDB, partido com tradição antipetista, teve 59 votos a favor e 7 contra (ESTADÃO, 2016)

Sem dúvida, a corrida eleitoral de 2018, tal como nas manifestações pró e contra o impeachment em 2016, foi marcada por fervorosa competitividade pelos adeptos das distintas propostas, consubstanciada em inúmeros protestos com multidões enraivecidas, disseminações de fake news, chacotas agressivas aos candidatos, representantes e partidos opostos, escândalos de corrupção, tensões sociais desviadas principalmente a temas de gênero e orientação sexual, manifestações de ataques físicos e violência psicológica nas ruas, ressentimentos gerados por publicações ofensivas nas redes sociais, alternância entre aplausos e resistências diante do ativismo do Supremo Tribunal Federal, "lutas" e "combates" engajados por apresentadores, jornalistas, youtubers, nas mais diversas mídias de entretenimento e notícias. Tudo isso, destaca-se, praticado devota e indiscriminadamente por membros de todos os "grupos" em disputa.

Diante disso, não obstante seja muito valorizada teoricamente tais oposições em nome de uma realidade dita "democrática", podem ser levantadas algumas críticas que envolvem o ideal democrático baseado na deliberação pública, em especial quando o contexto envolve uma 
polarização de grupos. É o que o presente artigo pretende analisar, examinando algumas consequências das deliberações coletivas, aqui percebidas como antidemocráticas no cenário da polarização política brasileira. Para tanto, a abordagem será desenvolvida a partir do método indutivo, com o objetivo explicativo e o procedimento bibliográfico, partindo de observações sobre a relação entre grupos, as deliberações no tribunal do júri e os pressupostos defendidos na ideia de democracia deliberativa, a fim de serem percebidas certas falhas nos níveis moral e epistêmico das deliberações coletivas em um contexto de radical extrapolação nas posturas de grupos com visões diferentes entre si.

No primeiro tópico serão abordadas teorias sobre o comportamento humano nas relações entre grupos e será analisada a ocorrência da sua polarização como fator de aumento da conflitualidade - com base em autores das áreas da psicologia social, da neurociência, das ciências sociais, políticas e antropológicas. No ponto seguinte, serão apresentados os principais pressupostos da ideia de democracia deliberativa, notadamente a partir das exposições do jurista Carlos Santiago Niño. Em um terceiro momento, serão examinados aspectos práticos relativos ao processo de deliberação coletiva em um contexto democrático, tendo como objeto de estudo a instituição do Tribunal do Júri, com base principalmente nas investigações de cientistas em psicologia social considerados autoridades proeminentes sobre aquele sistema de julgamento. Finalmente, no quarto tópico será possível refletir sobre a polarização dos grupos no contexto atual da política brasileira e os seus efeitos nas deliberações coletivas.

Por fim, importa salientar que absolutamente não se considera a deliberação coletiva como anti-democrática em si mesma, mas, conforme será exposto, alguns efeitos (re)produzidos durante a deliberação podem ser vistos como o espelho de elementos antidemocráticos existentes na sociedade. São reconhecidos os valores morais e intelectivos da teoria da democracia deliberativa e a sua legitimidade para validar as normas no cenário democrático. Não obstante, a análise negativa sobre alguns dos seus efeitos é uma abordagem que, embora não seja tão frequente, também é merecedora de atenção, não apenas para a reflexão sobre o contexto político atual do país, mas até mesmo para o seu próprio enfrentamento. Esclarece-se, ainda, que o presente artigo não pretende defender ou criticar qualquer um dos ideais perseguidos por quaisquer dos "grupos" apresentados, mas tão-somente examinar as causas e consequências atinentes à sua rivalidade no contexto deliberativo. 


\section{A polarização e o conflito integrupal}

Para tratar sobre o comportamento humano no âmbito de discussões coletivas entre grupos (como os "antipetistas" e os "petistas" brasileiros), é necessário recorrer, nesse momento, a algumas considerações sobre os relacionamentos entre grupos e o seu fenômeno conflitivo, através do exame de algumas teorias levantadas por estudos principalmente da área da psicologia social.

A partir de uma perspectiva psicológica, esclarece-se que "o conflito entre grupos é a percebida incompatibilidade de objetivos ou valores entre dois ou mais indivíduos, que surge porque esses indivíduos se classificam como membros de diferentes grupos" (BOHM; RUSCH; BARON, 2018, p. 10).

Para tratar do comportamento e conflito entre grupos, são pressupostos os conceitos de "grupo" e de "identificação de grupo", conforme elucida Henri Tajfel. Sobre o critério interno para alcançar a identificação, o autor explica que há dois elementos necessários: “um cognitivo, no sentido de consciência de pertencimento, e um valorativo, no sentido de que esta consciência está relacionada a conotações de valor” (TAJFEL, 1982, p. 02). No entanto, refere que esse "critério interno é uma condição necessária para a existência do grupo, no sentido psicológico do termo; mas não é suficiente para o surgimento do comportamento entre grupos", exigindo-se "também algum consenso exterior de que o grupo existe" (TAJFEL, 1982, p. 02), sendo tal condição exterior, sozinha, igualmente insuficiente.

Uma vez delimitado o significado de "grupo" e "conflito entre grupos", passa-se a examinar algumas teorias que tratam das manifestações dos componentes de um grupo entre si e entre os grupos externos e seus respectivos componentes, para fins de compreender a conflitualidade decorrente. Adianta-se que "os conflitos entre grupos afetam as percepções (e.g., estereotipagem, preconceito), emoções (e.g., medo, ódio), e comportamentos (e.g., discriminação, agressão) dos indivíduos envolvidos" (BOHM; RUSCH; BARON, 2018, p. 11).

No início do século XX (1906), Sumner havia apontado que os sentimentos existentes dentro de um grupo estão diretamente relacionados com os direcionados ao grupo externo (SUMNER, 1906, p. 13). Nota-se que a própria percepção humana sobre atitudes e sentimentos próprios e alheios é paradoxal, em razão da chamada "assimetria de atribuição motora" [motive attribution asymmetry]. Os estudos que identificaram esse padrão mostram que, em conflitos intergrupais políticos "os adversários tendem a atribuir a própria agressividade do grupo mais a um amor do grupo interno do que a um ódio ao grupo externo e atribuem a agressividade dos grupos externos a um ódio ao grupo externo superior ao amor do grupo interno" (WAYTZ; 
YOUNG; GINGES, 2014, p. 15687). Segundo teorizam os pesquisadores, "essa assimetria de atribuição motora pode estar associada a crenças específicas que minam a resolução de conflitos, incluindo a crença na intransigência inalterável do grupo externo" (WAYTZ; YOUNG; GINGES, 2014, p. 15688).

A partir de uma teoria realista dos conflitos entre grupos, entendeu-se que as hostilidades surgiam a partir das competições e tensões pelos chamados "recursos limitados", expressão que se refere a "qualquer percepção de que, dentro de uma sociedade, o acesso a recursos pode ser limitado para um grupo. Os recursos envolvidos podem incluir recursos econômicos, como dinheiro e empregos, bem como recursos menos tangíveis, como poder e prestígio" (ESSES; DOVIDIO, et. al. 2004, p. 100). Para comprovar a hipótese, sob a coordenação de Muzafer Sherif, realizou-se um dos maiores experimentos sobre conflitos entre grupos, o chamado "Caverna dos Ladrões" [Robbers Cave], descrito não apenas como um estudo psicológico e social, mas como uma verdadeira "antropologia experimental" (CAMPBELL, 1988, p. XX), no qual se demonstrou que os efeitos da participação em grupos preponderam sobremaneira sobre as relações interpessoais. Explica-se.

$\mathrm{Na}$ primeira fase do experimento, meninos foram levados para um acampamento isolado, no qual foram feitas várias atividades que permitiam o seu contato e a formação de agrupamentos por amizade. Na segunda, os meninos foram divididos a fim de separar as amizades, e foram realizadas atividades que tinham um objetivo comum apelativo a todos os meninos, cuja consecução exigia a participação cooperativa dentro do grupo. Na terceira fase, os dois grupos foram reunidos em situações competitivas, o que, dentro do grupo, resultou na solidariedade e em interações democráticas, mas, fora do grupo, "hostilidade, xingamento e até brigas entre os grupos surgiram, indicando que a democracia dentro do grupo necessariamente não leva a relações democráticas com os de fora quando as relações entre os grupos são repletas de condições propícias à tensão" (SHERIF; HARVEY; et. al. 1988, p. 11).

Em contraste com a teoria realista do comportamento entre grupos, a teoria da identidade social sustenta que não seria sequer necessária uma competição por recursos para que os conflitos se manifestassem, na medida em que isso ocorreria naturalmente a partir da identificação em um grupo e da presença de um grupo externo. Henri Tajfel relata um dos experimentos de Sherif, no qual, em dois grupos separados, os meninos haviam ido ao acampamento de férias: "assim que os grupos tomaram ciência da existência um do outro, e 
antes da competição entre eles ser instituída pelas autoridades do acampamento, havia algumas evidências do desenvolvimento de atitudes competitivas entre os grupos" (TAJFEL, 1982, p. 23).

Importa destacar que, como um dos principais aspectos do comportamento entre os grupos apontados por Tajfel, está a comprovada tendência de negação pelos membros de um grupo da individualidade dos membros do grupo de fora, isto é, da consideração sobre eles “como 'itens indiferenciados em uma categoria social unificada'. O estágio final desse processo é a 'despersonalização' e a 'desumanização' do grupo de fora, o que frequentemente acontece em condições desagradáveis de tensão" (TAJFEL, 1982, p. 21).

Também é possível falar em uma teoria da ameaça integrada, que considera ambas as anteriores como fontes do conflito entre os grupos, compreendendo "a ideia de que a forte identificação com o grupo interno predispõe as pessoas a reagirem a ameaça com preconceito, e a ideia de que contato negativo antecipa os sentimentos de ameaça", (STEPHAN; STEPHAN, 2000, p. 37), sendo que "as pessoas que fortemente se identificam com os seus grupos são mais propensas a experimentar maiores sentimentos de ameaça dos grupos externos do que aquelas cuja identidade é menos ligada na associação" (STEPHAN; STEPHAN, 2000, p. 37).

A teoria da identidade social também foi complementada pela da reciprocidade generalizada, na qual se estabelece que "os membros do grupo interno são mais propensos a cooperar uns com os outros a fim de manterem uma reputação positiva, para que eles possam continuar a se beneficiar por pertencer ao grupo" (BOHM; RUSCH; BARON, 2018, p. 18).

De acordo com essa teoria, "as pessoas deveriam expressar o favoritismo do grupo mais nas situações em que o seu parceiro está bem informado sobre o grupo ao qual pertencem (e os benefícios da reputação podem acrescentar), em comparação a quando o parceiro não sabe o grupo do participante" (BALLIET; WU; DREU, 2014, p. 1.573). Nesse sentido, confirmouse que há "maior discriminação entre grupos sob conhecimento comum em comparação ao conhecimento unilateral do grupo do parceiro" (BALLIET; WU; DREU, 2014, p. 1.573). Mas, de certa forma contrariando a exigência de um dos elementos imprescindíveis para a teoria da identidade social, também se percebeu que as "pessoas cooperam mais com os membros do seu grupo em comparação a estranhos não classificados, o que sugere que a presença de um grupo externo não é necessária para surgir o favoritismo na cooperação dentro do grupo" (BALLIET; WU; DREU, 2014, p. 1571-1572). 
Por fim, há, ainda, a teoria do "altruísmo paroquial", ${ }^{1}$ que explica as tendências de favoritismo dentro do grupo interno e de hostilidade com os grupos externos como um legado das adaptações ocorridas ao longo da evolução do homem. Samuel Bowles, realizando experimentos através de simulações computadorizadas da história humana, constatou que "entre os humanos ancestrais, altruístas paroquiais podem ter provocado conflitos entre grupos sobre recursos naturais e reprodutivos escassos, e ao mesmo tempo contribuíram para o sucesso do grupo nesses conflitos” (BOWLES, 2008, p. 326). Essa linha é seguida por antropologistas evolucionistas, cujos "estudos comparativos de primatas e outras espécies examinam a agressão entre grupos dentro de um contexto filogenético que abrange dezenas de milhões de anos" (GLOWACKI; WILSON; WRANGHAM, 2017, p. 02). Compreendem eles que "a estreita relação filogenética entre chimpanzés e humanos sugere a possibilidade de que padrões semelhantes de hostilidade entre grupos resultem de ancestralidade compartilhada" (GLOWACKI; WILSON; WRANGHAM, 2017, p. 07).

Por todo o exposto, não é surpresa, então, que, nas relações dos grupos uns com os outros, "existe uma maior quantidade de cooperação com o grupo interno do que com relação aos membros do grupo externo nos dilemas sociais" (BALLIET; WU; DREU, 2014, p. 1.574). Inclusive, já se comprovou que, "no geral, os participantes confiam nos membros do grupo interno mais do que nos membros do grupo externo" (HUGHES; AMBADY; ZAKI, 2017, p. 376), cujos resultados foram atribuídos, por estudos recentes, a mecanismos psicológicos que, inclusive, diferem em espécie, não em grau (HUGHES; AMBADY; ZAKI, 2017, p. 377)

No contexto de um cenário social no qual estão compreendidos grupos distintos que naturalmente controvertem entre si, ocorre a denominada "polarização", cuja importância para o presente estudo diz respeito ao seu efeito: "o nível de conflito aumenta com o nível de polarização" (ESTABAN; SCHNEIDER, 2008, p. 133). O termo "polarização" se refere à existente dominância de dois grupos opostos em um contexto social e ao efeito de os indivíduos intensificarem a posição, que já detinham, de maneira ainda mais extrema quando identificados em um dos grupos. Isso porque, “enquanto os membros do grupo mostram identificação uns com os outros em uma sociedade polarizada, eles se sentem social ou ideologicamente separados dos membros de outros grupos" (ESTABAN; SCHNEIDER, 2008, p. 133).

\footnotetext{
${ }^{1}$ Os termos da expressão são explicados: "o altruísmo é conferir benefícios aos outros por um custo para si mesmo; paroquialismo é favorecer internos étnicos, raciais ou outros sobre os de fora. Ambos são comportamentos humanos comumente observados que estão em documentados em experimentos". (BOWLES, 2008, p. 326)
} 
Estaban e Debraj elucidam que a polarização, e, por conseguinte, o aumento dos conflitos, vai ocorrer quando os seguintes aspectos forem observados: "Aspecto 1: deve existir um alto grau de homogeneidade dentro de cada grupo. Aspecto 2: deve existir um alto grau de heterogeneidade entre os grupos. Aspecto 3: deve existir um pequeno número de grupos de tamanho significante" (ESTABAN; RAY, 1994, p. 824). Também para Omar McDoom, existem "quatro mecanismos psicossociais em trabalho na polarização em grupo", a saber a "ativação da delimitação" [do grupo interno], a "negatividade do grupo externo", a "homogeneização do grupo externo" e a "solidariedade do grupo interno" (MCDOOM, 2012, p. 122).

John Turner explica o efeito da polarização pela referência ao fenômeno das ciências químicas e físicas: "como moléculas polarizadas, os membros de um grupo se tornam ainda mais alinhados na direção em que já tendiam” (TURNER, 1987, p. 142). A polarização do grupo, no viés psicológico relacionado à tomada de decisões, "foi definida como a tendência de a discussão em grupo alterar as atitudes individuais em direção ao polo, que é, em uma escala de classificação, o mais perto da média das respostas individuais" (HEWSTONE; JASPARS, 1984, p. 381). Entende-se que, pela polarização, as pessoas, que já têm predisposições anteriores, ao tomarem uma decisão individual, tornam-se mais confiantes de sua posição ser moralmente correta quando integrantes de um grupo que compartilha posições extremas no mesmo sentido (HEATH; GONZALES, 1995, p. 323). É importante para o presente estudo salientar que "o problema com a polarização do grupo é que a alteração da opinião é dirigida pelas dinâmicas de grupo ao invés da razão" (TALISSE, 2017, p. 112).

Observa-se que "a saliência da identificação social partidária é fortemente relacionada à polarização comportamental entre grupos" (PARSONS, 2015, p. 694), tal como se verifica nos grupos brasileiros classificados como direita e esquerda, sendo que "além da identificação de alguém com um grupo social, a extensão para a qual essa identificação é compartilhada, e talvez reforçada por pares em uma rede política, serve para ampliar as diferenças nas atitudes sobre o grupo interno e o grupo externo" (PARSONS, 2015, p. 694).

Daí porque se considera possível atribuir ao cenário atual brasileiro a qualificação de polarizado, em razão da divisão, intensamente ideológica e predominantemente não violenta, dos indivíduos em dois grandes grupos distintos de posições extremas (a "direita" "anti-PT" e a "esquerda" "PT" e "ele-não"), o que o torna ainda mais sujeito à conflitualidade. Inclusive, para o cientista político Fernando Bizzarro, o resultado das eleições presidenciais em 2018 refletiu "o clima de polarização mais extremado nos últimos anos" (ALMEIDA, 2018). 
Portanto, seja pela presença de situações de tensão e competição, pela influência psicológica da identificação, pela manutenção de reputações e o usufruto dos seus benefícios, pela adaptação de padrões de comportamento ao longo do tempo, ou, ainda, seja pela constituição biológica e química do ser humano, cada qual com as suas premissas distintas, todas as teorias ora observadas sugerem que os conflitos entre grupos e as diferenças de manifestações, percepções e sentimentos do indivíduo em relação ao grupo interno e ao externo são uma realidade que só aumenta pela ocorrência da polarização. Juntas, essas teorias podem contribuir para o esclarecimento de comportamentos e conflitos entre grupos polarizados, inclusive no campo político brasileiro.

\section{A democracia deliberativa e a deliberação coletiva}

Para o fim de possibilitar a análise dos fenômenos conflitivos entre grupos polarizados no processo de deliberação coletiva, faz-se necessário apontar algumas considerações gerais sobre o ideal de democracia deliberativa, conceito que aponta a deliberação coletiva como uma razão epistêmica em prol da legitimidade da tomada de decisões em geral, e, especificamente, das leis sancionadas em regimes políticos consensualmente eleitos. Merece destaque, para as posteriores reflexões, principalmente alguns dos elementos e pressupostos da referida deliberação, tais como a argumentação, a igualdade e a coletividade.

No que toca à tomada de decisões moralmente corretas através da deliberação, Carlos Santiago Niño distingue três princípios epistemológicos na busca do conhecimento da verdade moral. $\mathrm{O}$ autor atribui a Habermas a tese epistemológica segundo a qual a verdade moral pode ser acessada exclusivamente através do método de discussão e decisão coletiva "uma vez que a reflexão monológica é sempre distorcida pelo viés do indivíduo em favor de seu próprio interesse ou do interesse das pessoas próximas a ele devido ao condicionamento contextual e a dificuldade insuperável de se colocar na situação de outro" (NIÑO, 1997, p. 161). Dessa forma, a reflexão individual, nesse contexto de necessário envolvimento coletivo, "pode, no máximo, apenas resultar em uma contribuição para a discussão coletiva” (NIÑO, 1997, p. 162).

Não obstante, o autor refuta a teoria habermasiana ao entender que ela "parece conduzir a um populismo moral já que apoia a posição de que uma solução respaldada por todos ou pela maioria é automaticamente correta. É óbvio que a maioria às vezes apoia posições muito equivocadas" (NIÑO, 1997, p. 165). Assim, em sua teoria metaética, Niño defende um princípio 
epistemológico intermediário entre uma reflexão exclusivamente individual e uma tomada de posição coletiva para o conhecimento da verdade moral, admitindo a discussão e a decisão coletivas como o procedimento mais confiável, mas não excluindo a possibilidade de a reflexão individual representar corretamente os conflitos de interesses e chegar a uma conclusão correta e imparcial (NIÑO, 1997, p. 161 e 165).

Pode-se entender como um dos principais elementos do processo de tomada de decisão coletiva a argumentação. Defende-se que todo participante "justifique suas propostas em frente aos demais. Se os seus interesses são postos sobre a mesa, eles devem demonstrar que são legítimos" (NIÑO, 1997, p. 171). Assim, admite-se que simplesmente apoiado em "fatores emocionais e negociações com base no interesse próprio, o debate racional e as consequentes decisões majoritárias não tenderiam a ser soluções imparciais. Porém, o impacto benéfico destes aspectos da democracia sobre o seu valor moral só funciona através da argumentação" (NIÑO, 1997, p. 171).

Sobre a existência de uma dimensão afetiva da comunicação no contexto da discussão moral, Niño contempla o seu papel como "auxiliar ao valor epistêmico do processo de argumentação e decisão coletiva" (NIÑO, 1997, p. 175). Apesar de admitir que existem fatores emocionais que operam contrariamente ao descobrimento da verdade moral, considera que “existem modos relevantes em que as emoções ajudam ao progresso de um processo genuíno de argumentação. Elas impulsionam em primeiro lugar a discussão moral e nos movem a convencer os outros da verdade de nossas posições” (NIÑO, 1997, p. 175). Ressalta-se que, para ele, as emoções também contribuem para o processo de argumentação "através das sanções informais de atribuição de culpa e isolamento social que recai sobre aqueles que cometem erros evidentes ou faltas, que resultam em sua própria conveniência, no processo de argumentação" (NIÑO, 1997, p. 176).

O autor também apresenta a negociação, subjacente ao processo de argumentação, como processo importante, embora sem valor independente, no contexto democrático, pois "a dinâmica de negociação com suas ameaças e contribuições pode ajudar a alcançar a imparcialidade do processo de argumentação" (NIÑO, 1997, p. 177). Para que a negociação possa contribuir para o valor epistêmico da argumentação e decisões majoritárias, "uma minoria particular não pode permanecer sempre isolada como consequência de que os demais a abandonem sem importar o resultado da negociação. Tal minoria se constituiria em uma minoria congelada devido a sempre permanecer fora da maioria” (NIÑO, 1997, p. 177). 
A partir disso, Niño defende uma visão de democracia “em que é atribuído um papel a negociação e as manifestações emocionais, mas mantendo para elas um lugar subordinado à argumentação na promoção do poder epistêmico do processo de tomada das decisões majoritárias” (NIÑO, 1997, p. 170-171). A deliberação argumentativa na democracia é o motor que tornaria possível proporcionar "argumentos para crer, com justificação, que há motivos para agir; o valor do procedimento democrático provê razões para acatar os seus resultados, incluindo quando se dúvida sobre a sua justiça ou correção moral” (NIÑO, 1997, p. 170).

Segundo Cohen, sobre a concepção de democracia deliberativa, na qual se prioriza a deliberação coletiva para a tomada de decisões legítimas, "esse conceito de justificação por meio do raciocínio público - o núcleo do ideal democrático deliberativo - pode ser representado em um procedimento idealizado de deliberação política, construído para capturar as visões de liberdade, igualdade e raciocínio que figuram no ideal democrático deliberativo" (COHEN, 1999, p. 396). Da mesma forma, Habermas explica que "os sujeitos de direitos assumem o papel de autores de sua ordem jurídica através [...] da participação, em igualdade de chances, em processos de formação da opinião e da vontade, nos quais os civis exercitam sua autonomia política" (HABERMAS, 1997, p. 159), ressaltando-se que a participação “deve garantir que os interesses e orientações valorativas tenham o mesmo peso nas negociações" (HABERMAS, 1997, p. 226).

Isso porque "a comunhão das convicções obtidas discursivamente pelo legislador político se expressa na figura do poder comunicativo" (HABERMAS, 1997, p. 198), diante do que "todos os membros têm que poder tomar parte no discurso, mesmo que os modos sejam diferentes; Cada um deve ter basicamente as mesmas chances de tomar posição" (HABERMAS, 1997, p. 227). Dessa forma, destaca-se que, para a democracia deliberativa, o processo de deliberação não pode ser excludente, isto é, deve ser conduzido por todos os interessados, e não por uma elite de representantes de interesses específicos. Assim, devem ser supostas a igualdade nas razões apresentadas (e consideradas pelos participantes do processo) e a autoridade de todos eles, ambas em um sentido epistemológico.

A partir dessas considerações, percebe-se que os defensores do ideal deliberativo entendem como constitutivas e essenciais algumas condições epistemológicas para o alcance de decisões moralmente corretas através da deliberação coletiva, tais como: a participação de todas as partes interessadas na discussão, sedimentada em uma base razoável de igualdade e 
numa carga irrestrita de liberdade; o livre expressar de seus interesses; a justificação transparente com argumentos genuínos (NIÑO, 1997, p. 180).

\section{Os grupos e as deliberações democráticas na prática: o Tribunal do Júri}

No contexto do presente trabalho, a escolha pelo Tribunal do Júri para observar alguns aspectos relativos à dinâmica da deliberação coletiva decorre do fato de que, em realidade, "nenhuma outra instituição do governo compete com o júri em colocar poder tão diretamente nas mãos dos cidadãos. Logo, nenhuma outra instituição arrisca tanto na democracia ou aposta mais na verdade da reivindicação central da democracia de que o povo é o melhor governante para si mesmo" (ABRAMSON, 2000, p. 01-02). Segundo Lynn Sanders "se a política norteamericana é alguma vez realmente considerada democrática, isso é na instituição do júri: os júris deveriam capturar o que há de melhorar sobre a democracia norte-americana" (SANDERS,1997, p. 363)

Daí porque se utiliza desse objeto de estudo para inferir aspectos da democracia deliberativa, na medida em que "no júri, os cidadãos invocam as suas faculdades racionais e consideram um problema comum, ou ao menos impessoal, não pessoal" (SANDERS,1997, p. 363). Além disso, "no ideal, as deliberações do júri são caracterizadas por uma vigorosa troca de informação, garantindo uma oportunidade para todos os membros de expressar os seus respectivos pontos de vista" (KASSIN; WEIGHTSMAN, 2013, p. 11)

Já no início das deliberações dos jurados, que começam com a escolha do líder ou primeiro-jurado, há observações a serem consideradas sobre a seleção: "mais frequentemente, a chance de liderar o júri é maior para um homem branco com trabalho de ensino superior ou pós-graduação, em uma ocupação de alto status e com prévio serviço no júri (HANS; VIDMAR, 1986, p. 101). Phoebe Ellsworth relata que "embora 65 por cento dos jurados fossem mulheres, dezesseis em dezoito primeiro-jurados eram homens. Nos júris compostos de onze mulheres e um homem, o homem era escolhido" (ELLSWORTH, 1995, p. 60). A autora também destaca que alegar ter experiência prévia é um fator importante para as chances de ser selecionado como primeiro-jurado, razão pela qual "o processo de seleção do primeiro-jurado pode ser resumido pela frase "escolha um homem que diz ter experiencia" (ELLSWORTH, 1995, p. 60).

Diante disso, nos estudos sobre as deliberações dos júris, observa-se que "os jurados frequentemente trazem conhecimento pessoal bem como experiências pessoais mais diretas para abordar o caso em questão" (HANS; VIDMAR, 1986, p. 107), sendo que "o status na sala do júri espelha o status no mundo exterior" (HANS; VIDMAR, 1986, p. 100-101). No entanto, 
esses fatores de gênero, raça e privilégios econômicos característicos não é, segundo Lynn Sanders, direta e imediatamente o que determina a seleção do primeiro jurado, pois, "ao invés disso, eles aumentam a probabilidade do comportamento que leva a seleção como chefe do júri” (SANDERS 1997, p. 364). Essas características acabam por refletir na participação de determinados jurados ao longo de todas as tomadas de decisão pelo júri, pois "em média, homens falam mais do que mulheres, assim como fazem nessa deliberação. Aqueles com mais educação e ocupação de mais alto status também tendem a dominar a discussão" (HANS; VIDMAR, 1986, p. 108).

Merece destaque uma consideração aparentemente óbvia sobre as deliberações para o veredito: “todos os jurados não contribuem igualmente para a discussão. Em teoria, cada jurado deveria ter uma voz igual na deliberação e no veredito, mas, na prática, existem vastas diferenças no quanto os jurados falam” (HANS; VIDMAR, 1986, p. 108). Tanto o é que o resultado das pesquisas com júris simulados "revela que a maioria dos júris incluem várias pessoas que praticamente nunca participam na deliberação. Elas têm pouco impacto no processo de tomada de decisão; a sua única contribuição pode ser participar na votação" (HANS; VIDMAR, 1986, p.108).

Além disso, esses participantes considerados "fracos" acabam normalmente se identificando em subgrupos que compartilham a mesma preferência de veredito, sendo que “quanto maior a facção da qual o jurado pertence, menor é a probabilidade do jurado falar. Se apenas um ou dois jurados representam certa posição, eles tendem a ser bem ativos na deliberação; mas se um grande número de jurados segue uma posição, eles tendem a falar menos" (HANS; VIDMAR, 1986, p. 108). Até agora foi possível perceber que nem todos falam e, por conseguinte, nem todos têm participação ou influência na deliberação.

No que toca ao conflito entre grupos no âmbito da deliberação do júri, observa-se que o grupo de jurados, antes tratado como um todo, acaba se dividindo em subgrupos com a mesma visão sobre o caso: “enquanto essas facções se formam, o modo e o teor da conversa muda. Agora, os jurados perguntam uns aos outros sobre as bases para as visões opostas, desafiam as percepções divergentes dos outros jurados, e justificam a sua própria posição" (HANS; VIDMAR, 1986, p. 108). Fica claro que o procedimento do júri pode ser tratado como um verdadeiro processo deliberativo democrático, entre cidadãos identificados em grupos. Nesse contexto, o que se observa é que "esse tipo de conflito pode tornar os jurados desconfortáveis. 
Não apenas eles estão presos em uma sala com praticamente estranhos com quem eles discordam, mas também eles devem chegar a um consenso ou bloquear o júri antes que eles sejam liberados" (HANS; VIDMAR, 1986, p. 108).

Por fim, ponto relevante também diz respeito ao questionamento sobre toda essa deliberação ser normalmente apta a alterar a opinião inicial dos jurados. Não se nega que isso até seja possível, embora a experiência de Henry Fonda no filme "Doze Homens e Uma Sentença" - cuja argumentação é capaz de abalar a certeza pela condenação dos outros onze jurados - e a de Demi Moore em "A Jurada" - cujas exigências sofridas para manipular todo o júri são cumpridas com êxito - não sejam aptas a reproduzir a realidade. Isso porque "as investigações mostram repetidamente que o melhor indicador da decisão final de um júri é a distribuição de opinião entre os jurados no começo das deliberações" (HANS; VIDMAR, 1986, p. 110). Ou seja, normalmente prevalece a maioria, sendo que "a primeira votação, mediante cédula, vai frequentemente revelar qual será o veredito final” (HANS; VIDMAR, 1986, p. 107). Assim, a deliberação é comparada à revelação do filme da câmera fotográfica: "ela traz à luz a imagem, mas o resultado é pré-determinado" (KALVEN; ZEISEL, 1966, p. 489).

\section{Os efeitos problemáticos da deliberação coletiva entre grupos polarizados}

Viu-se que o ideal moral da democracia deliberativa pode compreender cidadãos iguais e ativos envolvidos em um processo no qual todos podem ou devem falar e serem necessariamente ouvidos. Além de um ideal moral, trata-se de um conceito epistêmico, como bem estabelece Niño, na medida em que envolve a apresentação de razões que pesam para a tomada das decisões. No entanto, a partir das considerações feitas nesse artigo, viu-se que incidem fatores do mundo prático que contrastam com essas exigências da deliberação democrática, tanto no nível moral, quanto no epistêmico.

A falha em relação ao aspecto moral pode ser observada pelo fato de que "os cidadãos não são capazes ou não são inclinados a se engajar uns com os outros civilmente em questões políticas" (TALISSE, 2017, p. 112). Analisa-se isso didaticamente por duas perspectivas, uma que diz respeito à tendência do próprio indivíduo em relação à própria deliberação política e a outra concernente ao indivíduo identificado em grupo, principalmente quando polarizado.

No viés individual, é preciso considerar um outro ponto estudado por Ilya Somin, que diz respeito à "teoria da ignorância racional". Segundo a autora, existem “cidadãos que seguem a política porque acham divertido ou porque, como fãs de esporte, desfrutam 'torcer' pelo seu 'time' político" (SOMIN, 2010, p. 262-263) e "igualmente, muitas pessoas adquirem 
conhecimento político com o objetivo de conformar as suas visões pré-existentes ou satisfazer um senso de superioridade sobre as pessoas com opiniões diferentes" (SOMIN, 2010, p. 263). O problema, ou falha, no ideal moral da deliberação acontece justamente quando "esses motivos conflitam com o objetivo de valoração racional de informação com o propósito de tomar decisões políticas informadas" (SOMIN, 2010, p. 263). Explica-se que "as pessoas que adquirem informação para o propósito de torcer para o seu 'time' político ou confirmar as suas visões existentes provavelmente sobrevalorizam informações que confirmam essas visões e depreciam ou ignoram qualquer coisa que corte contra eles" (SOMIN, 2010, p. 263).

No contexto do grupo, ao longo do primeiro tópico deste artigo, viu-se, com mais detalhes, que os indivíduos se comportam de maneira diferente quando identificados em grupos, razão pela qual a interação entre os grupos, por exemplo, em um processo de deliberação, pode se tornar conflituosa, conforme o nível de polarização entre eles. O fenômeno da polarização está ligado à inclinação da posição anterior dos indivíduos ao extremo quando em grupo e ao "amor" ao grupo interno e "ódio" ao grupo externo, o que se reflete especialmente nas emoções, percepções e comportamentos dos seus membros, tais como desconfiança, desacordo, rejeição, desvalorização, preconceito, em relação ao grupo adversário e seus respectivos componentes.

Quando os cidadãos efetivamente se engajam uns com os outros para uma deliberação, percebe-se, então, a falha epistemológica, na medida em que "se engajam de maneiras gravemente aquém das expectativas dos ideais epistêmicos de deliberação pública (julgamentos e votantes melhor informados, decisões políticas melhor fundamentadas, melhor entendimento público das políticas públicas, maior prestação de contas, etc.)” (TALISSE, 2017, p. 112).

A deliberação ocorrida entre pessoas epistemicamente desiguais produz a dinâmica da polarização. Como se viu, a partir das considerações práticas feitas sobre o sistema do júri, algumas pessoas simplesmente falam mais do que outras nas deliberações, diante do que os participantes não são considerados iguais ou não tem seus argumentos igualmente considerados, tal como pretende a noção de deliberativa coletiva de seus defensores. Contudo, mesmo que todas as pessoas comprometidas na deliberação pudessem igualmente apresentar razões - o que seria difícil de imaginar, dadas as diferenças de persuasão argumentativa inerentes aos indivíduos ou aquelas socialmente produzidas - as manifestações de alguns, independentemente do conteúdo em questão, ainda assim prevaleceriam sobre as dos outros, sem que os próprios indivíduos envolvidos no processo se dessem conta disso, já que se trata 
de um padrão que, manifestado pela própria identificação a um grupo, independe de uma intenção humana a ele dirigida. Isso porque, como a ciência já comprova, quando os indivíduos estão identificados em grupos, principalmente em um contexto polarizado, eles simplesmente tendem a acolher, concordar, confiar naquilo que vêm de membros do grupo interno, bem como a rejeitar, discordar, ignorar e desconfiar do que parte do grupo externo. Nesse sentido, não se mostra irrazoável considerar que aquelas "sanções informais de atribuição de culpa" que Niño referia como meio das emoções contribuírem para a argumentação na deliberação não necessariamente se manifestariam, em razão da própria ausência de percepção do problema.

Haveria igualmente dificuldades na proposta de deliberação individual de Niño, apresentada por um ou alguns atendendo todas as perspectivas e interesses dos silentes. Isso porque tal poderia não surtir o efeito pretendido, pois, novamente, quando os indivíduos têm identificação por um grupo - tal como se sustenta que eles têm no Brasil -, tendem naturalmente a repelir ainda mais os "interesses" dos outros que estejam fora do seu escopo e, por consequência, dificilmente se colocariam "no lugar do outro". Ainda, as razões apresentadas na deliberação, mesmo que atendessem todas as perspectivas e interesses, não necessariamente pesariam para alterar a posição predisposta de alguns na hora de votar para a tomada de decisão. É o que acontece no procedimento do júri, na medida em que, mesmo após as incessantes deliberações dos jurados, sabe-se que a regra geral é a de que o veredito final corresponde à opinião majoritária do momento anterior ao desenvolvimento das discussões.

Além disso, essa desigualdade epistêmica conduz à consideração da falta de condições epistêmicas de autoridade e competência de alguém para apresentar suas razões, sendo que essa intolerância também pode ser incrementada pelo fato de que o comportamento entre grupos polarizados possibilita a despersonalização e desumanização dos membros do grupo externo. Robert Talisse ilustra essa negação de capacidade epistêmica: “porque os grupos se polarizam, eles se tornam menos capazes de tolerar a possibilidade de desacordo fundamentado e sincero; visões opostas são ouvidas como um barulho confuso, as críticas começam a parecer covardes e ignorantes, e a visão favorecida pelo grupo passa a ser vista como a única visão racional possível” (TALISSE, 2017, p. 113). Segundo o autor, a polarização dos grupos "não apenas dissolve a civilidade, mas também desabilita a deliberação pública ao encorajar a ideia entre os cidadãos de que, em última instância, não há nada a deliberar porque o desacordo razoável não é, de fato, possível" (TALISSE, 2017, p. 113). Os adeptos de visões rivais não debatem, mas meramente desafiam a "competência, sanidade e aptidão para a cidadania" um do outro (TALISSE, 2017, p.110). 


\section{Considerações Finais}

Viu-se que o ideal moral da democracia deliberativa compreende necessariamente cidadãos iguais e ativos envolvidos em um processo no qual todos os interessados devem se manifestar e serem necessariamente ouvidos. Além de um ideal moral, trata-se de um conceito epistêmico, como bem estabelece Niño, na medida em que envolve a apresentação, pelos cidadãos, de razões, ideias e argumentos que pesam para a tomada das decisões.

No entanto, a partir das considerações feitas nesse artigo, identificou-se que a dinâmica da polarização e do conflito entre grupos (vivenciados e extrapolados no cenário político brasileiro) contrasta com essas exigências, tanto no nível moral, quanto no âmbito epistêmico. Através da deliberação em assembleias públicas, são geralmente realizadas performances que reproduzem os padrões de exclusão e preconceito que existem no respectivo cenário social.

Tal como Joseph Schumpeter já advertira, embora com imagens extremas, de que os indivíduos "são terrivelmente fáceis de transformar-se em um grupo psicológico e em um estado de frenesi no qual a tentativa de argumentação racional apenas estimula os espíritos animais" (SCHUMPETER, 2003, p. 257), a realidade parece apontar justamente para a circunstância de que "não se pode combater uma perniciosa dinâmica de grupo com uma boa razão" (SANDERS, 1997, p. 254).

Daí porque, no processo deliberativo, a dinâmica da polarização dos grupos em conflito acaba por produzir efeitos antidemocráticos, e o "governo do povo" acaba se tornando o governo de alguns, pois nessa situação, embora em tese o voto tenha o mesmo peso, as razões para o voto, como visto, definitivamente não atuam da mesma maneira. E, ao final, a regra é a de que o voto depois das deliberações não deixa de ser aquela escolha adotada anteriormente ao escrutínio.

\section{Referências Bibliográficas}

ABRAMSON, Jeffrey. We, the jury. the jury sistem and the ideal of democracy: with a new preface. Harvard University Press: Cambridge, 2000

ALMEIDA, Marco Rodrigo. Ascensão de Bolsonaro sela a crise de legitimidade dos partidos, diz pesquisador. Folha de São Paulo, 8 out. 2018. 
BALLIET, Daniel; WU, Junhui; DREU, Carsten De. Ingroup favoritism in cooperation: a metaanalysis. Psycological Bulletin, Washington, v. 140, n. 6, p. 1556-1581, 2014.

BOHM, Robert; RUSCH, Hannes; BARON, Jonathan. The psychology of intergroup conflict: a review of theories and measures. Journal of Economic Behavior \& Organization, Amsterdam, 2018

BOWLES, Samuel. Conflict: altruism's midwife. Nature, London, v. 456, nov. 2008.

CAMPBELL, Donald. Introduction to the wesleyan edition. In. SHERIF, Muzafer; HARVEY, O.J.; et. al. Intergroup conflict and cooperation: the robbers cave experiment. Middletown: Wesleyan University Press, 1988.

COHEN, Joshua. Reflections on habermas on democracy. Ratio Juris, Hoboken, v. 12, n. 4, p. 385-416, dez. 1999

ELLSWORTH, Phoebe C. Are twelve heads better than one? Law Quadrangle Notes, Ann Arbor, v. 38, n. 2, p. 56-64, 1995.

ESSES, Victoria; DOVIDIO, John; et. al. Social psychology of prejudice: historical and modern perspectives on group competition. In. CRANDALL, Christian; SCHALLER, Mark. (Org.) Social psychology of prejudice: historical and contemporary issues. Lawrence: Lewinian Press, 2004.

ESTABAN, Joan Maria; RAY, Debraj. On the measurement of polarization. Econometrica: journal of the Econometric Society Econometric Society, Chicago, v. 62, n. 4, p. 819-851, jul. 1994

ESTABAN, Joan Maria; SCHNEIDER, Gerald. Polarization and conflict: theoretical and empirical issues. Journal of Peace Research, Thousand Oaks, v. 45, n. 2, p. 131-141, 2008 
GLOWACKI, Luke; WILSON, Michael; WRANGHAM. The evolutionary antropology of war. Journal of Economic Behavior \& Organization, Amsterdam, 2017.

HABERMAS, Jurgen. Direito e democracia. entre facticidade e validade, volume I. Tradução: Flávio Beno Siebeneichler. Rio de Janeiro: Tempo Brasileiro, 1997

HANS, Valerie P.; VIDMAR, Neil. Judging the jury. New York: Springer Science + Business Media, 1986

HEATH, Chip; GONZALES. Rich. interaction with others increases decision confidence but not decision quality: evidence against information collection views of interactive decision making. Organizational Behavior and Human Decision Processes, Amsterdam, v. 61, n. 3, p. 305-326, mar. 1995

HEWSTONE, Miles; JASPARS, Joseph. Social dimensions of attribution. In. TAJFEL, Henri (Org.). European studies in social psychology. the social dimension, volume 2. New York: Cambridge University Press, 1984

HUGHES, Brent L.; AMBADY, Nalini; ZAKI, Jamil. Trusting outgroup, but not ingroup members, requires control: neural and behavioral evidence. Social Cognitive and Affective Neuroscience, Oxford, v. 12, n. 3, p. 372-381, 2017.

KALVEN, Harry; ZEISEL, Hans. The american jury. Boston: Little Brown, 1966

KASSIN, Saul; WEIGHTSMAN, Lawrence. The american jury on trial: psychologial perspectives. New York: Taylor \& Francis, 2013

MCDOOM, Omar Shahabudin.The psychology of threat in intergroup conflict: emotions, rationality, and opportunity in the rwandan genocide. International Security, Cambridge, v. 37, n. 2, p. 119-155, 2012 
NIÑO, Carlos Santiago. La constitución de la democracia deliberativa. Gedisa: Barcelona, 1997.

PARSONS, Bryan. The social identity politics of peer networks. American Politics Research, Eastleigh v. 43, n. 4, p. 680-707, 2015

Placar do impeachment. Estadão. 2016. Disponível em <http://infograficos.estadao.com.br/politica/placar-do-impeachment/>. Acesso: 29 dez. 2018

SANDERS, Lynn M. Against deliberation. Political Theory, Thousand Oaks, v. 25, n. 3, p. 347-376, jun. 1997.

SCHUMPETER, Joseph A. Capitalism, socialism \& democracy. London: Routledge, 2003

SHERIF, Muzafer; HARVEY, O.J.; et. al. Intergroup conflict and cooperation: the robbers cave experiment._Middletown: Wesleyan University Press, 1988

SOMIN, Ilya. Deliberative democracy and political ignorance. Critical Review, New York, v. 22 , n. $2-3$, p. $253-279,2010$

STEPHAN, Walter; STEPHAN, Cookie White. An integrated threat theory of prejudice. In. Oskamp, S. (Org.). Reducing prejudice and discrimination. Mahwah: Lawrence Erlbaum Associates, 2000

SUMNER, William Graham. Folkways. a study of the sociological importance of usages, manners, customs, mores, and morals. Boston: The Athaenaeum Press, 1906.

TAJFEL, Henri. Social psychology of intergroup relations. Annual Review of Psycology, Palo Alto, v. 33, p. 1-39, 1982.

TALISSE, Robert. New trouble for deliberative democracy. Les ateliers de l'éthique, Montréal, v. 12, n. 1, p. 107-123, 2017 
TURNER, John. Rediscovering the social group: self-categorization theory. Oxford: Oxford, 1987

WAYTZ, Adam; YOUNG, Liane; GINGES, Jeremy. Motive attribution asymmetry for love vs. hate drives intractable conflict. Psychological and Cognitive Sciences, Fairfax, v. 44, p. 15687-15692, nov. 2014 